\title{
OPEN Normal weight obesity and the risk of diabetes in Chinese people: a 9-year population-based cohort study
}

\author{
Shaoyong $\mathrm{Xu}^{1,2,6}$, Jie Ming ${ }^{3,6}$, Aihua $\mathrm{Jia}^{4,6}$, Xinwen $\mathrm{Yu}^{3}$, Jing $\mathrm{Cai}^{5}$, Ce Jing ${ }^{3}$, Chun Liu ${ }^{3}$ \& \\ Qiuhe $\mathrm{Ji}^{\mathrm{i}}{ }^{\mathrm{B}}$
}

We evaluated the risk of developing diabetes in Chinese individuals with normal weight obesity (NWO). This 9-year population-based cohort study was based on the China National Diabetes and Metabolic Disorders Survey. A total of 1128 subjects without diabetes were included. Body fat percentage (BF\%) was assessed by electrical bioimpedance. NWO was defined as subjects with a normal BMI $\left(<24 \mathrm{~kg} / \mathrm{m}^{2}\right)$ and an excess BF\% ( $\geq 24 \%$ in men; $\geq 33 \%$ in women). Of 1128 individuals, 528 individuals were normal weight non-obese (NWNO), 118 (10.5\%) were normal weight obese (NWO), 63 were overweight non-obese (OWNO), and 419 were overweight obese (OWO). During a follow-up of 9.0 years (interquartile range: 8.9-9.3), $113(10.0 \%)$ individuals developed diabetes. The incidence rates of diabetes in NWNO, NWO, OWNO and OWO people were 5.69 (27 cases), 11.30 (12 cases), 3.53 ( 2 cases) and 19.09 (72 cases) per 1000 person-years, respectively. Cox regression analyses indicated multivariate-adjusted hazard ratios of diabetes in NWO, OWNO and OWO people were $2.110(95 \%$ $\mathrm{Cl} 1.026-4.337, p=0.025), 0.441(95 \% \mathrm{Cl} 0.101-1.928, p=0.232)$ and $3.465(95 \% \mathrm{Cl} 2.163-5.551$, $p<0.001)$, respectively, relative to NWNO people. Chinese people with NWO are at increased risk of developing diabetes. We strongly suggest the incorporation of BF\% measurement into the regular physical examination in Chinese medical practice.

During the past three decades, obesity has become a worldwide epidemic that threatens public health. The prevalence of obese and overweight adults increased by 27.5\% from 1980 to 2013, going from 857 million in 1980 to 2.1 billion in $2013^{1}$. Obesity confers a substantial increased risk for morbidity and mortality, particularly from diabetes and cardiovascular diseases ${ }^{2-5}$. However, the current concept of obesity, defined by weight and height measures, has been challenged by evidence indicating this may not accurately identify all obesity-related diseases. This has led to the introduction of a new phenotype, called "normal weight obesity" (NWO) that describes individuals with a normal body mass index $(\mathrm{BMI})$ but increased body fat percentage $(\mathrm{BF} \%)^{6}$.

Strong evidence exists linking NWO and cardiometabolic dysregulation, cardiovascular disease and overall mortality rates ${ }^{7}$. NWO is associated with insulin resistance, low insulin sensitivity, and high insulin secretion ${ }^{8}$. However, due to a lack of BF\% measurements in most large epidemiologic surveys, few cross-sectional studies regarding the association between NWO and diabetes have been conducted and results of these few are controversial $^{8,9}$. For example, one cross-sectional study showed that NWO women had a higher prevalence of fasting hyperglycemia (odds ratio $[\mathrm{OR}]=1.63,95 \%$ confidence interval $[\mathrm{CI}] 1.10-2.42$ ) than lean women ${ }^{8}$, while another study showed that NWO was not significantly associated with high blood glucose (OR: 1.60, 95\% CI 0.54-4.76, $p=0.395)^{9}$. More importantly, fewer cohort studies exist ${ }^{10}$. One community-based cohort study reported that subjects with normal $\mathrm{BMI}$ but increased $\mathrm{BF} \%$ had a higher risk of developing diabetes ${ }^{10}$. Thus, population-based cohort studies with long-term follow-up periods are especially needed to clarify the association between NWO and diabetes, and to provide data applicable to the broader population.

\footnotetext{
${ }^{1}$ Department of Health Statistics, Shaanxi Key Laboratory of Free Radical Biology and Medicine and the Ministry of Education Key Lab of Hazard Assessment and Control in Special Operational Environment, School of Public Health, Air Force Medical University, Xi'an, China. ${ }^{2}$ Department of Endocrinology, Xiangyang Central Hospital, Affiliated Hospital of Hubei University of Arts and Science, Xiangyang, China. ${ }^{3}$ Department of Endocrinology, Endocrinology Research Center, Xijing Hospital, Air Force Medical University, Xi'an 710032, China. ${ }^{4}$ Department of Endocrinology, No.1 Hospital of Yulin, Yulin, China. ${ }^{5}$ College of Basic Medicine, Shaanxi University of Chinese Medicine, Xianyang, China. ${ }^{6}$ These authors contributed equally: Shaoyong Xu, Jie Ming and Aihua Jia. ${ }^{\bowtie}$ email: qiuheji@hotmail.com
} 


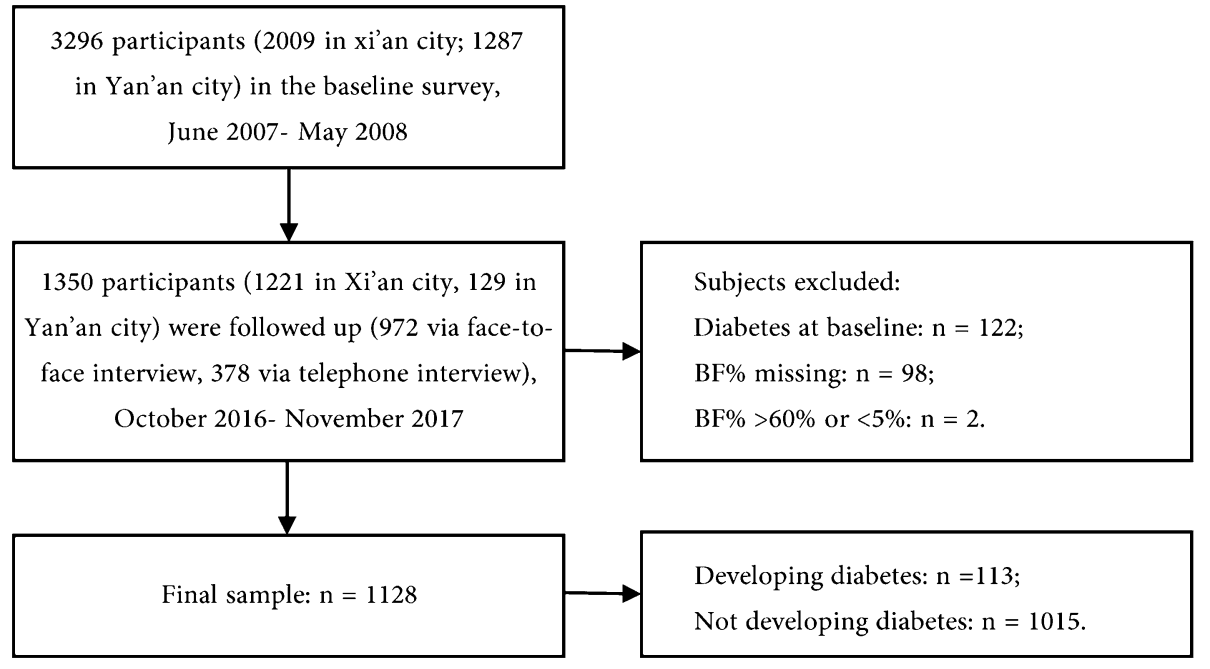

Figure 1. Flowchart of the study population. BF\% body fat percentage.

We thus conducted a prospective population-based cohort study to evaluate the risk of developing diabetes for a Chinese population with NWO.

\section{Results}

The study sample included 1128 individuals without diabetes, with $42.3 \%$ male, a mean age of 41.66 years, a mean BMI of $23.65 \mathrm{~kg} / \mathrm{m}^{2}$, and a mean BF\% of $29.17 \%$. During the 9-year (interquartile range: 8.9-9.3) follow-up, 113 $(10.0 \%)$ individuals developed diabetes, of whom 92 were diagnosed based on the oral glucose tolerance test (OGTT) and 21 diagnoses were based on self-reported diabetes history or use of hypoglycemic drugs (Fig. 1).

Within the study sample, 528 individuals were considered normal weight non-obese (NWNO), 118 (10.5\%) were classified as normal weight obese (NWO), 63 were classified as overweight non-obese (OWNO), and 419 were diagnosed as overweight obese (OWO). Compared with NWNO individuals, NWO individuals were more likely to be older, male, to have higher blood pressure, and higher levels of glucose, total cholesterol, LDL cholesterol and triglycerides. Baseline measures are provided according to BMI and obesity phenotypes in Table 1. Compared with individuals who did not develop diabetes, individuals who developed diabetes during follow-up had a higher baseline age, BMI, BF\%, blood pressure, glucose level and triglyceride levels (Table 2).

The incidence rates of diabetes in NWNO, NWO, OWNO and OWO people were 5.69 (27 cases), 11.30 (12 cases), 3.53 ( 2 cases) and 19.09 (72 cases) per 1000 person-years, respectively. Cox regression analyses indicated multivariate-adjusted hazard ratios (HRs) of diabetes in NWO, OWNO and OWO people were 2.110 (95\% CI 1.026-4.337, $p=0.025$ ), 0.441 (95\% CI: $0.101-1.928, p=0.232$ ) and 3.465 (95\% CI 2.163-5.551, $p<0.001$ ), respectively, compared to NWNO people. In male participants, NWO was not significantly associated with diabetes compared to NWNO (HR: 1.163, 95\% CI 0.314-4.301, $p=0.821$ ), while in female participants, a significant association between NWO and diabetes occurred (HR: 3.102, 95\% CI 1.372-7.014, $p=0.007$ ) (Table 3).

Sensitivity analyses were conducted by excluding participants in the study site with a low follow-up rate or by excluding participants with baseline pre-diabetes $(n=218)$; results were similar to the full data set in both cases. Excluding participants with baseline metabolic syndrome (MS) $(n=299)$ or participants with only a telephone interview $(n=340)$, gave similar HRs but effects were no longer statistically significant, partly due to sample size insufficiency. Details are given in Table 4.

\section{Discussion}

We previously reported that the optimal foot-to-foot BIA-measured BF\% cutoff in Chinese people is $24 \%$ for men and $33 \%$ for women. The prevalence of NWO is $7.39 \%$ based on these criteria ${ }^{11,12}$. In the present study, we conduct a 9-year longitudinal survey and show that Chinese people with NWO had an approximately two times greater risk of developing diabetes (HR: 2.110, 95\% CI 1.026-4.337, $p=0.025$ ) compared to NWNO controls. Overweight people with normal BF\% did not have an increased risk of diabetes (HR: 0.441, 95\% CI 0.101-1.928, $p=0.232$ ). The strengths of this study include that it is a population-based sample, has a long-term follow-up period, diagnosed diabetes based on OGTT, excluded individuals with diabetes at baseline, and adjusted for several potentially confounding factors.

Our results showed that people with NWO have a significantly increased risk of developing diabetes. Only a few cross-sectional studies have previously explored the association between NWO and insulin resistance, hyperglycemia or diabetes, but the results were equivocal ${ }^{8,9}$. For example, Madeira et al. studied 1222 males and females aged 23-25 years and showed that NWO was significantly associated with a homeostasis model assessment-insulin resistance $(\mathrm{OR}=3.81,95 \% \mathrm{CI} 1.57-9.82)$ but not with high blood glucose (OR: $1.60,95 \% \mathrm{CI}$ $0.54-4.76, p=0.395)^{8}$. In contrast, a cross-sectional study conducted by Marques-Vidal et al. with 3213 women and 2912 men aged 35-75 years in Switzerland, suggested that NWO women had a higher prevalence of fasting 


\begin{tabular}{|c|c|c|c|c|c|c|}
\hline & Total & $\begin{array}{l}\text { Normal weight } \\
\text { non-obesity }\end{array}$ & $\begin{array}{l}\text { Normal weight } \\
\text { obesity }\end{array}$ & $\begin{array}{l}\text { Overweight non- } \\
\text { obesity }\end{array}$ & Overweight obesity & p value \\
\hline$N$ & 1128 & 528 & 118 & 63 & 419 & \\
\hline \multicolumn{7}{|c|}{ Demographic characteristics } \\
\hline Age, years & $43.89 \pm 12.35$ & $41.66 \pm 12.71$ & $42.86 \pm 12.12$ & $48.83 \pm 11.21$ & $46.26 \pm 11.48$ & $<0.001$ \\
\hline Male, n (\%) & $477 / 1128(42.3)$ & $171 / 528(32.4)$ & $56 / 118(47.5)$ & $43 / 63(68.3)$ & $207 / 419(49.4)$ & $<0.001$ \\
\hline \multicolumn{7}{|c|}{ Educational level, n (\%) } \\
\hline College or above & $343 / 1120(30.6)$ & $203 / 525(38.7)$ & $29 / 117(24.8)$ & $20 / 62(32.3)$ & $91 / 416(21.9)$ & $<0.001$ \\
\hline $\begin{array}{l}\text { Smoking history, } \\
\mathrm{n}(\%)\end{array}$ & $263 / 1127(23.3)$ & $101 / 528(19.1)$ & $23 / 117(19.7)$ & $26 / 63(41.3)$ & $113 / 419(27.0)$ & $<0.001$ \\
\hline $\begin{array}{l}\text { Drinking history, } \\
\mathrm{n}(\%)\end{array}$ & $254 / 1120(22.7)$ & $90 / 525(17.1)$ & $31 / 117(26.5)$ & $23 / 62(37.1)$ & $110 / 416(26.4)$ & $<0.001$ \\
\hline $\begin{array}{l}\text { Physical activity, } \\
\text { n (\%) }\end{array}$ & $450 / 1121(40.1)$ & $223 / 527(42.3)$ & $39 / 117(33.3)$ & $27 / 62(43.5)$ & $161 / 415(38.8)$ & 0.272 \\
\hline $\begin{array}{l}\text { Family history of } \\
\text { diabetes, } \mathrm{n}(\%)\end{array}$ & $133 / 1128(11.8)$ & $66 / 528(12.5)$ & $12 / 118(10.2)$ & $13 / 63(20.6)$ & $42 / 419(10.0)$ & 0.088 \\
\hline Body weight, kg & $61.89 \pm 10.82$ & $54.88 \pm 6.94$ & $59.42 \pm 6.76$ & $68.61 \pm 7.44$ & $70.38 \pm 9.54$ & $<0.001$ \\
\hline $\begin{array}{l}\text { Body mass index, } \\
\mathrm{kg} / \mathrm{m}^{2}\end{array}$ & $23.65 \pm 3.29$ & $21.09 \pm 1.74$ & $22.75 \pm 1.23$ & $25.25 \pm 1.04$ & $26.88 \pm 2.34$ & $<0.001$ \\
\hline Body fat percent, $\%$ & $29.17 \pm 7.81$ & $24.36 \pm 5.17$ & $31.43 \pm 4.97$ & $24.65 \pm 5.12$ & $35.27 \pm 7.00$ & $<0.001$ \\
\hline \multicolumn{7}{|c|}{ Clinical characteristics } \\
\hline $\begin{array}{l}\text { Systolic blood pres- } \\
\text { sure, } \mathrm{mm} \mathrm{Hg}\end{array}$ & $119.42 \pm 19.66$ & $113.18 \pm 17.97$ & $115.99 \pm 16.63$ & $123.63 \pm 15.13$ & $127.65 \pm 20.01$ & $<0.001$ \\
\hline $\begin{array}{l}\text { Diastolic blood pres- } \\
\text { sure, mm Hg }\end{array}$ & $75.24 \pm 11.23$ & $71.82 \pm 9.91$ & $74.50 \pm 11.18$ & $75.67 \pm 9.63$ & $79.72 \pm 11.51$ & $<0.001$ \\
\hline $\begin{array}{l}\text { Fasting plasma } \\
\text { glucose, } \mathrm{mmol} / \mathrm{L}\end{array}$ & $5.10 \pm 0.65$ & $5.03 \pm 0.65$ & $5.06 \pm 0.64$ & $5.09 \pm 0.66$ & $5.21 \pm 0.66$ & $<0.001$ \\
\hline $\begin{array}{l}2 \mathrm{~h} \text { postprandial } \\
\text { glucose, } \mathrm{mmol} / \mathrm{L}\end{array}$ & $6.02 \pm 1.55$ & $5.76 \pm 1.47$ & $5.76 \pm 1.34$ & $5.89 \pm 1.39$ & $6.42 \pm 1.64$ & $<0.001$ \\
\hline $\begin{array}{l}\text { Total cholesterol, } \\
\mathrm{mmol} / \mathrm{L}\end{array}$ & $4.71 \pm 0.91$ & $4.51 \pm 0.88$ & $4.71 \pm 0.88$ & $4.74 \pm 0.86$ & $4.95 \pm 0.92$ & $<0.001$ \\
\hline $\begin{array}{l}\text { LDL cholesterol, } \\
\mathrm{mmol} / \mathrm{L}\end{array}$ & $2.64 \pm 0.75$ & $2.47 \pm 0.73$ & $2.69 \pm 0.67$ & $2.66 \pm 0.65$ & $2.85 \pm 0.77$ & $<0.001$ \\
\hline $\begin{array}{l}\text { Triglyceride, } \\
\mathrm{mmol} / \mathrm{L}\end{array}$ & $1.53 \pm 1.09$ & $1.21 \pm 0.82$ & $1.37 \pm 0.78$ & $1.79 \pm 1.09$ & $1.95 \pm 1.30$ & $<0.001$ \\
\hline
\end{tabular}

Table 1. Baseline characteristics of study participants by obesity phenotypes. $L D L$ low-density lipoprotein.

hyperglycemia $(\mathrm{OR}=1.63,95 \% \mathrm{CI} 1.10-2.42)$ than lean women ${ }^{9}$. Our results from the current study are similar to a previous Chinese cohort study in which Zhao et al. conducted a community-based study of 1857 normal glucose tolerance subjects that were followed for 44.57 months. Compared with individuals having normal BF\% and BMI, subjects with normal BMI but increased BF\% had a higher risk of developing diabetes (Relative risk [RR]: 4.790, 95\% CI 1.061-21.621) ${ }^{10}$. Differences in RRs between Zhao et al. and our study might be due to differences in study design, duration of follow up, control group, and baseline metabolic state of the subjects included.

In addition, we found that overweight people with normal BF\% did not have an increased risk of diabetes (HR: $0.441,95 \%$ CI $0.101-1.928, p=0.232$ ). The results agree with those of Zhao et al. ${ }^{10}$, who found that those with stable normal BF\% and abnormal BMI did not have a significantly higher risk of developing diabetes $(\mathrm{RR}=2.838$, 95\% CI 0.293-27.537). The possible existence of healthy obesity has been a subject of debate for many years because some overweight and obese individuals are found to have a metabolically healthy status ${ }^{13}$. However, meta-analyses indicates that adults with metabolically heathy obesity (MHO) have substantially increased risks of developing diabetes and cardiovascular events compared with metabolically healthy normal-weight adults ${ }^{14,15}$, and prospective evidence does not indicate that healthy obesity is a harmless condition. Thus, data corroborate the concept that MHO is one step in the process of obesity whereby individuals are likely to become metabolically unhealthy ${ }^{16}$. Nonetheless, the key point is that obesity judged by BMI is problematic, because BMI does not take into account a person's bone, muscle, or fat proportions, and thus fat mass and fat-free mass are not differentiated with $\mathrm{BMI}^{17}$. In fact, a person with a higher BMI but normal BF\% is more likely to take part in strength training or be an athlete. For example, in the National Football League (NFL), 97\% of all players have a BMI of $\geq 25.0 \mathrm{~kg} /$ $\mathrm{m}^{2}$, but based on BF\% only $8.9 \%$ of these athletes are obese and $14.5 \%$ have below-normal $\mathrm{BF} \%{ }^{18}$. Thus, $\mathrm{BF} \%$ is a more accurate measure for identification of obesity-related diabetes risk in populations such as athletes, and clinical focus should be on BF\% rather than BMI.

A previous nationwide population-based cohort study with a mean follow-up of 8.8 years showed that NWO was associated with high prevalence of cardiometabolic dysregulation, metabolic syndrome, and cardiovascular risk factors. In women, NWO is independently associated with increased risk for cardiovascular mortality ${ }^{7}$. Those findings, together with our own, drew our attention to NWO, as a special phenotype of obesity. Since obesity is defined as a condition where there is an excess of body fat ${ }^{19}$, as opposed to excess weight (in fact, excess BMI), 


\begin{tabular}{|c|c|c|c|}
\hline Variable & Developing diabetes & Not developing diabetes & $p$ value \\
\hline$n$ & 113 & 1013 & \\
\hline \multicolumn{4}{|l|}{ Demographic characteristics } \\
\hline Age, y & $48.92 \pm 10.43$ & $43.31 \pm 12.41$ & $<0.001$ \\
\hline Male, n (\%) & $54 / 113(47.8)$ & $423 / 1014(41.7)$ & 0.229 \\
\hline \multicolumn{4}{|l|}{ Educational level, n (\%) } \\
\hline College or above & $26 / 112(23.2)$ & $317 / 1007(31.5)$ & 0.229 \\
\hline Smoking history, n (\%) & $29 / 113(25.7)$ & $234 / 1013(23.1)$ & 0.558 \\
\hline Drinking history, n (\%) & $25 / 112(22.3)$ & $229 / 1007(22.7)$ & 1.000 \\
\hline Physical activity, n (\%) & $49 / 113(43.4)$ & $401 / 1007$ (39.8) & 0.480 \\
\hline Family history of diabetes, $\mathrm{n}(\%)$ & $20 / 113(17.7)$ & 113/1014 (11.1) & 0.046 \\
\hline Body weight, kg & $67.25 \pm 11.37$ & $61.31 \pm 10.57$ & $<0.001$ \\
\hline Body mass index, $\mathrm{kg} / \mathrm{m}^{2}$ & $25.61 \pm 3.27$ & $23.44 \pm 3.96$ & $<0.001$ \\
\hline Body fat percent, $\%$ & $33.13 \pm 8.17$ & $28.74 \pm 7.65$ & $<0.001$ \\
\hline \multicolumn{3}{|l|}{ Clinical characteristics } & $<0.001$ \\
\hline Systolic blood pressure, $\mathrm{mm} \mathrm{Hg}$ & $126.95 \pm 17.87$ & $118.56 \pm 19.67$ & $<0.001$ \\
\hline Diastolic blood pressure, $\mathrm{mm} \mathrm{Hg}$ & $79.91 \pm 10.25$ & $74.71 \pm 11.21$ & $<0.001$ \\
\hline Fasting plasma glucose, mmol/L & $5.23 \pm 0.69$ & $5.09 \pm 0.65$ & 0.027 \\
\hline $2 \mathrm{~h}$ postprandial glucose, $\mathrm{mmol} / \mathrm{L}$ & $7.03 \pm 1.67$ & $5.90 \pm 1.49$ & $<0.001$ \\
\hline Total cholesterol, mmol/L & $4.81 \pm 0.82$ & $4.70 \pm 0.92$ & 0.218 \\
\hline LDL cholesterol, mmol/L & $2.73 \pm 0.80$ & $2.64 \pm 0.75$ & 0.187 \\
\hline Triglyceride, $\mathrm{mmol} / \mathrm{L}$ & $2.10 \pm 1.58$ & $1.47 \pm 1.00$ & $<0.001$ \\
\hline
\end{tabular}

Table 2. Baseline characteristics of study participants by development of diabetes. $L D L$ low-density lipoprotein.

\begin{tabular}{|c|c|c|c|c|}
\hline & Normal weight non-obesity & Normal weight obesity & Overweight non-obesity & Overweight obesity \\
\hline \multicolumn{5}{|l|}{ Total participants } \\
\hline Cases/participants, n/N & $27 / 527$ & $12 / 118$ & $2 / 63$ & $72 / 419$ \\
\hline Incidence, $\%$ & 5.1 & 10.2 & 3.2 & 17.2 \\
\hline Crude HR (95\% CI) & 1.000 & $2.087(1.052-4.143)$ & $0.505(0.120-2.129)$ & $4.011(2.553-6.303)$ \\
\hline$p$ value & & 0.035 & 0.352 & $<0.001$ \\
\hline Adjusted HR (95\% CI) & 1.000 & $2.110(1.026-4.337)$ & $0.441(0.101-1.928)$ & $3.465(2.163-5.551)$ \\
\hline$p$ value & & 0.025 & 0.232 & $<0.001$ \\
\hline \multicolumn{5}{|l|}{ Male participants } \\
\hline Cases/participants, n/N & $10 / 171$ & $3 / 56$ & $1 / 43$ & $40 / 207$ \\
\hline Incidence, $\%$ & 5.8 & 5.4 & 2.3 & 19.3 \\
\hline Crude HR (95\% CI) & 1.000 & $1.086(0.294-4.016)$ & $0.332(0.042-2.635)$ & $4.063(1.970-8.382)$ \\
\hline$p$ value & & 0.902 & 0.297 & $<0.001$ \\
\hline Adjusted HR (95\% CI) & 1.000 & $1.163(0.314-4.301)$ & $0.307(0.039-2.427)$ & $4.167(2.014-8.620)$ \\
\hline$p$ value & & 0.821 & 0.263 & $<0.001$ \\
\hline \multicolumn{5}{|l|}{ Female participants } \\
\hline Cases/participants, n/N & $17 / 356$ & $9 / 62$ & $1 / 20$ & $32 / 212$ \\
\hline Incidence, $\%$ & 4.8 & 14.5 & 5.0 & 15.1 \\
\hline Crude HR (95\% CI) & 1.000 & $2.906(1.288-6.556)$ & $0.931(0.124-7.016)$ & $3.824(2.105-6.947)$ \\
\hline$p$ value & & 0.010 & 0.945 & $<0.001$ \\
\hline Adjusted HR (95\% CI) & 1.000 & $3.102(1.372-7.014)$ & $0.779(0.103-5.897)$ & $3.403(1.847-6.269)$ \\
\hline$p$ value & & 0.007 & 0.809 & $<0.001$ \\
\hline
\end{tabular}

Table 3. Cox regression analysis of obesity phenotypes in predicting type 2 diabetes mellitus in total, male, and female participants. CI confidence interval. ${ }^{\star}$ Hazard ratio and $95 \%$ CI were calculated using a backward stepwise method. The covariables were age, (gender), cigarette smoking, alcohol drinking, physical activities, family history of diabetes and baseline blood glucose levels. 


\begin{tabular}{|c|c|c|c|c|}
\hline & Normal weight non-obesity & Normal weight obesity & Overweight non-obesity & Overweight obesity \\
\hline $\begin{array}{l}\text { Population in sites with high } \\
\text { follow-up rates }\end{array}$ & $(\mathrm{n}=1044)$ & & & \\
\hline $\mathrm{n} / \mathrm{N}, \%$ & $25 / 490(5.1)$ & $12 / 111(10.8)$ & $2 / 59(3.4)$ & $70 / 384(18.2)$ \\
\hline Crude HR (95\% CI) & 1.000 & $2.177(1.092-4.341)$ & $0.521(0.123-2.200)$ & $4.025(2.538-6.383)$ \\
\hline Adjusted HR (95\% CI) & 1.000 & $2.280(1.143-4.548)$ & $0.422(0.100-1.791)$ & $3.756(2.362-5.973)$ \\
\hline $\begin{array}{l}\text { Population without baseline } \\
\text { pre-diabetes }\end{array}$ & $(\mathbf{n}=910)$ & & & \\
\hline $\mathrm{n} / \mathrm{N}, \%$ & $15 / 447(3.4)$ & $9 / 96(9.4)$ & $2 / 52(3.8)$ & $43 / 315(13.7)$ \\
\hline Crude HR $(95 \%$ CI $)$ & 1.000 & $2.024(1.306-7.002)$ & $0.948(0.215-4.176)$ & $4.982(2.707-9.170)$ \\
\hline Adjusted HR (95\% CI) & 1.000 & $3.113(1.344-7.212)$ & $0.756(0.171-3.351)$ & $4.750(2.571-8.778)$ \\
\hline $\begin{array}{l}\text { Population without baseline } \\
\text { MS }\end{array}$ & $(n=829)$ & & & \\
\hline $\mathrm{n} / \mathrm{N}, \%$ & $23 / 479(4.8)$ & $9 / 98(9.2)$ & $2 / 46(4.3)$ & $27 / 206(13.1)$ \\
\hline Crude HR (95\% CI) & 1.000 & $2.012(0.902-4.653)$ & $0.876(0.343-3.872)$ & $2.769(1.582-5.220)$ \\
\hline Adjusted HR (95\% CI) & 1.000 & $1.845(0.883-4.467)$ & $0.665(0.143-3.136)$ & $2.781(1.524-5.189)$ \\
\hline $\begin{array}{l}\text { Population with only office } \\
\text { follow-up }\end{array}$ & $(n=788)$ & & & \\
\hline $\mathrm{n} / \mathrm{N}, \%$ & $23 / 360(4.2)$ & $10 / 84(11.9)$ & $2 / 50(4.0)$ & $57 / 294(19.4)$ \\
\hline Crude HR (95\% CI) & 1.000 & $1.792(0.855-3.754)$ & $0.460(0.109-1.946)$ & $3.697(2.295-5.956)$ \\
\hline Adjusted HR (95\% CI) & 1.000 & $1.869(0.890-3.921)$ & $0.402(0.095-1.708)$ & $3.662(2.272-5.903)$ \\
\hline
\end{tabular}

Table 4. Sensitivity analyses. $R R$ relative risk, $C I$ confidence interval. ${ }^{\star}$ Hazard ratio and $95 \%$ CI were calculated using a backward stepwise method. The covariables were age, gender, cigarette smoking, alcohol drinking, physical activities, family history of diabetes, and baseline blood glucose levels.

the current concept of diagnosing obesity using BMI has been challenged. Early in 1981, Ruderman et al. defined a novel phenotype of obesity as metabolically obese normal weight (MONW). They described individuals with MONW as characterized by normal body weight and BMI, but with hyperinsulinemia and possibly an increase in fat cell size ${ }^{20}$. However, not all persons with normal body weight but high BF\% have this cluster of metabolic abnormalities, and, in 2005, De Lorenzo et al. formally introduced the term, NWO. We would emphasize that NWO is of greater concern than MONW, a condition that has been studied for some decades. In contrast to subjects with MONW, who present major metabolic changes that result in signs and symptoms as well as subsequent diagnosis $^{21}$, individuals with NWO are likely undiagnosed and thus unaware of the cardiometabolic risks they face. NWO screening using simple methods (e.g., foot-to-foot BIA) is thus strongly suggested in clinical practice.

Several limitations of the study should be addressed. First, although dual energy X-ray absorptiometry is considered the gold standard for BF\% measurement ${ }^{22}$, we used bioelectrical impedance in our study based on its acceptable accuracy, simplicity, lack of radiation, and relatively low $\operatorname{cost}^{23}$. Nevertheless, bioelectrical impedance may underestimate upper-body obesity ${ }^{24}$, we had a relatively low follow-up rate $(41.0 \%)$ for the entire sample. However, after excluding 177 individuals in the low-rate sites, the follow-up rate was $72.6 \%$ with a sample size of 1173, which is sufficient for a high-quality cohort study. We also conducted sensitivity analysis by excluding sites with low follow-up rate and showing results were similar. Third, misclassification may have happened in our study, since people could have had changes in their body composition during the follow-up period. This concern is true for most longitudinal studies which use baseline information on the exposure variable. Fourth, unmeasured and residual confounding effects cannot be eliminated although a range of potentially confounding factors were included. For example, information on dietary intake was not collected. Fifth, cases of incident diabetes and overweight non-obesity were small, so relevant conclusions need to be confirmed by future studies with larger sample sizes. Last, our findings from a single-province survey might not be generalizable to the whole country.

In conclusion, we demonstrate that Chinese people with NWO are at increased risk of developing diabetes. Our study shows that BF\% constitutes a better measure of obesity assessment than BMI. We strongly suggest incorporation of $\mathrm{BF} \%$ measurement into the regular physical examination, and NWO screening using simple methods in clinical practice in the Chinese population.

\section{Methods}

Study sample. This cohort study with a follow-up of 9 years was based on the China National Diabetes and Metabolic Disorders Study (CNDMDS). CNDMDS was a nationwide population-based cross-sectional survey, with aims to investigate the prevalence of diabetes and associated metabolic risk factors in China. The current cohort study included only individuals of CNDMDS in Shaanxi province, Northwestern China. During June 2007 and May 2008, we used a multi-stage stratified sampling method to select a representative sample from Shaanxi province, narrowing down the sample pool in four stages, as detailed previously ${ }^{25}$. Briefly, in the first stage, two cities (Xi'an as capital city and Yan'an as a non-capital city) were selected non-randomly. In the second stage, city districts from cities and rural townships from countryside were randomly selected. In the third stage, street districts from city districts and rural villages from townships were randomly selected. In the last stage, adults $\geq 20$ years were selected using stratified sampling methods according to the sex and age distribution. 
In total, 3296 subjects (2009 in Xi'an city and 1287 in Yan'an city) were selected as the baseline study sample and were invited to participate in the 9-year follow-up evaluation from October 2016 to November 2017. Of these, 1350 subjects (1221 in Xi'an city and 129 in Yan'an city) agreed and participated in the follow-up evaluation; 972 had a face-to-face evaluation and 378 were evaluated by telephone (21 were deceased). The total follow-up rate was $41.0 \%$ in all study sites; after excluding study sites with a low follow-up rate, the rate was $72.6 \%$ with a study sample size of 1173 . The details of follow-up rate for each study site are described in Table S1. Comparison of baseline data between participants who did and did not undergo follow-up examinations is provided in Table S2. We excluded subjects with diabetes $(n=122)$ diagnosed by oral glucose tolerance test (OGTT) or a history of antidiabetic medications at baseline. We also excluded 98 subjects with missing data for BF\% and two subjects with $\mathrm{BF} \%>60 \%$ or $<5 \%$. Ultimately, a total of 1128 subjects were included as our study sample for analysis (Fig. 1).

This study was approved by the Ethics Committee of Xijing Hospital, Affiliated Hospital of Fourth Military Medical University. All participants signed written informed consent prior to data collection. All methods were performed in accordance with the relevant guidelines and regulations.

Baseline data collection. During 2007-2008, using a standard questionnaire, trained physicians and nurses collected baseline data on demographic characteristics, lifestyle risk factors, personal medical history and family history of diseases ${ }^{26}$. Body size and obesity phenotype were evaluated including body height, body weight, waist circumference and BF\% measurement. Body weight was measured in kilograms on a calibrated digital scale and body height was measured using a stadiometer in centimeters with subjects wearing light clothes and without shoes. BF\% was assessed by electrical bioimpedance analysis (BIA) using the Tanita TBF-300 body composition analyser (Tanita Corporation, Tokyo, Japan) at baseline during 2007-2008. An OGTT was performed on all subjects. Subjects without history of diabetes were administered a standard 75-g glucose solution after at least $10 \mathrm{~h}$ of overnight fasting. For security reasons, subjects with a self-reported history of diabetes were given a steamed bun with approximately $80 \mathrm{~g}$ of complex carbohydrates. A hexokinase enzymatic method was used to measure serum glucose. Plasma lipid profiles, including total cholesterol, serum triglyceride and low-density lipoprotein (LDL) cholesterol were also measured from fasting blood samples by the enzymatic method. All laboratory measurements were conducted under conditions of a standardization and certification program ${ }^{25}$.

Assessment of obesity phenotype. Subjects were stratified into four groups according to baseline BMI and $\mathrm{BF} \%$. BMI was calculated by dividing body weight in kilograms by the square of body height in meters. The normal weight obese (NWO) group contained subjects with a normal BMI $\left(<24 \mathrm{~kg} / \mathrm{m}^{2}\right)$ and an excess BF\% $(\geq 24 \% \text { in men and } \geq 33 \% \text { in women })^{11}$. Subjects with a normal BMI $\left(<24 \mathrm{~kg} / \mathrm{m}^{2}\right)$ and normal BF\% $(<24 \%$ in men and $<33 \%$ in women) were placed in the normal weight non-obese (NWNO) group as controls. Subjects with a BMI $\geq 24 \mathrm{~kg} / \mathrm{m}^{2}$ were considered overweight, and included both overweight $\left(24 \mathrm{~kg} / \mathrm{m}^{2} \leq \mathrm{BMI}<28 \mathrm{~kg} / \mathrm{m}^{2}\right)$ and obese $\left(\mathrm{BMI} \geq 28 \mathrm{~kg} / \mathrm{m}^{2}\right)$ subjects. Overweight subjects with a normal $\mathrm{BF} \%$ were placed in the overweight non-obese (OWNO) group, and overweight subjects with an excess $\mathrm{BF} \%$ were in the overweight obese (OWO) group.

Assessment of covariates. Alcohol drinking was defined as consuming at least $30 \mathrm{~g}$ of alcohol per week for at least a year. Individuals that had consumed at least 100 cigarettes during their lifetime were classified as cigarette smoking. Regular leisure-time physical activity was defined as participation in moderate to vigorous activity for $30 \mathrm{~min}$ or more per day on at least 3 days a week. Education level was categorized as (1) below college or (2) college and above. Family history of disease was defined as at least one of parents or siblings diagnosed with a disease in their lifetime and based on self-reporting ${ }^{25}$. Blood pressure was measured using a mercury sphygmomanometer in a sitting position in the morning after at least $5 \mathrm{~min}$ of rest. Two consecutive measurements were performed and the mean of the measurements recorded.

Follow-up evaluation. The primary outcome was the incidence of diabetes with a follow-up of 9 years. For subjects receiving face-to-face evaluation at the follow-up survey, OGTT was performed to evaluate diabetes status, as described above. According to World Health Organization diagnostic criteria ${ }^{27}$, diabetes is defined as the use of antidiabetic medications, a fasting glucose level $\geq 7.0 \mathrm{mmol} / \mathrm{l}$, or a 2 -h glucose level $\geq 11.1 \mathrm{mmol} / \mathrm{l}$ after a $75 \mathrm{~g}$ OGTT. Pre-diabetes was defined as fasting glucose level between 6.1 and $6.9 \mathrm{mmol} / \mathrm{l}$, and/or a 2-h glucose level between 7.8 and $11.0 \mathrm{mmol} / \mathrm{l}$ after a $75 \mathrm{~g}$ OGTT. For individuals receiving follow-up interviews by telephone evaluation, diabetes was diagnosed by self-reporting.

Statistical analysis. Sample size requirement was estimated in advance using PASS 11.0 (NCSS, LLC, Utah, USA). Based on a previous study that indicated NWO individuals had a 4.8 -fold increased risk of diabetes (95\% CI 1.1-21.6 $)^{10}$, a sample size of 106-425 participants was planned to provide an $80 \%$ power with $95 \%$ confidence intervals $(\alpha=0.05)$, which corresponds to HRs of 2.0-4.0 (P0 was estimated as 5\%).

Data were summarized as the mean \pm standard deviation (SD) for normally distributed data, the median with interquartile range for skewed variables, or percentages, as suitable. Differences between groups in continuous variables were analyzed by a t-test or analysis of variance (ANOVA) as appropriate. Differences for enumeration data were assessed by the chi-square test of independence.

The incidence of diabetes was calculated for the NWNO, NWO, OWNO and OWO groups. To identify the impact of NWO on the risk of diabetes, a cox regression analysis was done and hazard ratios (HRs) with corresponding 95\% CI were obtained using a backward stepwise method. In addition, sensitivity analyses were conducted to assess the robustness of the results by re-running all the models with a subset of individuals excluded. 
All statistical analyses were performed using SPSS 18.0 (SPSS Inc., Chicago, IL, USA). All reported $P$ values are two-tailed, and statistical significance was set at a $P$-value $<0.05$.

Ethics approval and consent to participate. This study was approved by the Ethics Committee of Xijing Hospital, Affiliated Hospital of Fourth Military Medical University. All participant signed written informed consent prior to data collection.

Received: 31 October 2020; Accepted: 3 March 2021

Published online: 17 March 2021

\section{References}

1. Ng, M. et al. Global, regional, and national prevalence of overweight and obesity in children and adults during 1980-2013: A systematic analysis for the Global Burden of Disease Study 2013. Lancet (London, England) 384, 766-781 (2014).

2. Poirier, P. et al. Obesity and cardiovascular disease: pathophysiology, evaluation, and effect of weight loss: An update of the 1997 American Heart Association Scientific Statement on obesity and heart disease from the obesity committee of the council on nutrition, physical activity, and metabolism. Circulation 113, 898-918 (2006).

3. Pi-Sunyer, F. X. The obesity epidemic: Pathophysiology and consequences of obesity. Obes. Res. 10(Suppl 2), 97s-104s (2002).

4. Hubert, H. B., Feinleib, M., McNamara, P. M. \& Castelli, W. P. Obesity as an independent risk factor for cardiovascular disease: A 26-year follow-up of participants in the Framingham Heart Study. Circulation 67, 968-977 (1983).

5. Ortega, F. B., Lavie, C. J. \& Blair, S. N. Obesity and cardiovascular disease. Circ. Res. 118, 1752-1770 (2016).

6. Oliveros, E., Somers, V. K., Sochor, O., Goel, K. \& Lopez-Jimenez, F. The concept of normal weight obesity. Prog. Cardiovasc. Dis. 56, 426-433 (2014).

7. Romero-Corral, A. et al. Normal weight obesity: A risk factor for cardiometabolic dysregulation and cardiovascular mortality. Eur. Heart J. 31, 737-746 (2010).

8. Madeira, F. B. et al. Normal weight obesity is associated with metabolic syndrome and insulin resistance in young adults from a middle-income country. PLoS ONE 8, e60673 (2013).

9. Marques-Vidal, P. et al. Normal weight obesity: Relationship with lipids, glycaemic status, liver enzymes and inflammation. Nutr. Metab. Cardiovasc. Dis. NMCD 20, 669-675 (2010).

10. Zhao, T., Lin, Z., Zhu, H., Wang, C. \& Jia, W. Impact of body fat percentage change on future diabetes in subjects with normal glucose tolerance. IUBMB Life 69, 947-955 (2017).

11. Jia, A. et al. Body fat percentage cutoffs for risk of cardiometabolic abnormalities in the Chinese adult population: A nationwide study. Eur. J. Clin. Nutr. 72, 728-735 (2018).

12. Jia A, et al. Prevalence and cardiometabolic risks of normal weight obesity in Chinese population: A nationwide study. Nutr. Metab. Cardiovasc. Dis. 28, 1045e1053 (2018).

13. Smith, G. I., Mittendorfer, B. \& Klein, S. Metabolically healthy obesity: Facts and fantasies. J. Clin. Investig. 129, 3978-3989 (2019).

14. Eckel, N., Meidtner, K., Kalle-Uhlmann, T., Stefan, N. \& Schulze, M. B. Metabolically healthy obesity and cardiovascular events: A systematic review and meta-analysis. Eur. J. Prevent. Cardiol. 23, 956-966 (2016).

15. Bell, J. A., Kivimaki, M. \& Hamer, M. Metabolically healthy obesity and risk of incident type 2 diabetes: A meta-analysis of prospective cohort studies. Obes. Rev. 15, 504-515 (2014).

16. Soriguer, F. et al. Metabolically healthy but obese, a matter of time? Findings from the prospective Pizarra study. J. Clin. Endocrinol. Metab. 98, 2318-2325 (2013).

17. Willett, W. C., Dietz, W. H. \& Colditz, G. A. Guidelines for healthy weight. N. Engl. J. Med. 341, 427-434 (1999).

18. Provencher, M. T. et al. Body mass index versus body fat percentage in prospective national football league athletes: Overestimation of obesity rate in athletes at the national football league scouting combine. J. Strength Cond. Res. 32, 1013-1019 (2018).

19. Obesity: preventing and managing the global epidemic. Report of a WHO consultation. World Health Organization technical report series 894, i-xii, 1-253 (2000).

20. Ruderman, N. B., Schneider, S. H. \& Berchtold, P. The, “metabolically-obese," normal-weight individual. Am. J. Clin. Nutr. 34, 1617-1621 (1981).

21. Franco, L. P., Morais, C. C. \& Cominetti, C. Normal-weight obesity syndrome: Diagnosis, prevalence, and clinical implications. Nutr. Rev. 74, 558-570 (2016).

22. Fogelholm, M. \& van Marken, L. W. Comparison of body composition methods: A literature analysis. Eur. J. Clin. Nutr. 51, 495-503 (1997).

23. Snijder, M. B., van Dam, R. M., Visser, M. \& Seidell, J. C. What aspects of body fat are particularly hazardous and how do we measure them?. Int. J. Epidemiol. 35, 83-92 (2006).

24. Snijder, M. B., Kuyf, B. E. \& Deurenberg, P. Effect of body build on the validity of predicted body fat from body mass index and bioelectrical impedance. Ann. Nutr. Metab. 43, 277-285 (1999).

25. Yang, W. et al. Prevalence of diabetes among men and women in China. N. Engl. J. Med. 362, 1090-1101 (2010).

26. He, Y. et al. Regional variation limits applications of healthy gut microbiome reference ranges and disease models. Nat. Med. 24, $1532-1535$ (2018).

27. Alberti, K. G. \& Zimmet, P. Z. Definition, diagnosis and classification of diabetes mellitus and its complications. Part 1: diagnosis and classification of diabetes mellitus provisional report of a WHO consultation. Diabetic Med. J. Br. Diabetic Assoc. 15, 539-553 (1998).

\section{Acknowledgements}

We thank all of the physicians and participants of the study for their co-operation and generous participation. This study was partly supported by the Natural Science Foundation of Shaanxi Province, China (Grant No. 2013KTZB03-02-01). SX is supported by the China Postdoctoral Science Foundation (No. 2018M643837) and a Special Financial Grand from the China Postdoctoral Science Foundation (No. 2019T120986).

\section{Author contributions}

S.X., J.M. and A.J. contributed equally to the study. Q.J. and S.X. conceived and designed the study. S.X., J.M. and A.J. contributed to the data extraction, performed the analysis and interpreted the results. S.X. and A.J. wrote 
the first draft; X.Y., J.C., C.J., C.L., and Q.J. contributed to the revision of the final report. All authors read and approved the final manuscript.

\section{Competing interests}

The authors declare no competing interests.

\section{Additional information}

Supplementary Information The online version contains supplementary material available at https://doi. org/10.1038/s41598-021-85573-z.

Correspondence and requests for materials should be addressed to Q.J.

Reprints and permissions information is available at www.nature.com/reprints.

Publisher's note Springer Nature remains neutral with regard to jurisdictional claims in published maps and institutional affiliations.

(c) (i) Open Access This article is licensed under a Creative Commons Attribution 4.0 International License, which permits use, sharing, adaptation, distribution and reproduction in any medium or format, as long as you give appropriate credit to the original author(s) and the source, provide a link to the Creative Commons licence, and indicate if changes were made. The images or other third party material in this article are included in the article's Creative Commons licence, unless indicated otherwise in a credit line to the material. If material is not included in the article's Creative Commons licence and your intended use is not permitted by statutory regulation or exceeds the permitted use, you will need to obtain permission directly from the copyright holder. To view a copy of this licence, visit http://creativecommons.org/licenses/by/4.0/.

(C) The Author(s) 2021 